\title{
Carotid intima-media thickness and arterial stiffness in relation to cerebral small vessel disease in neurologically asymptomatic individuals with type 1 diabetes
}

\author{
Jussi Inkeri ${ }^{1,2} \cdot$ Anniina Tynjälä2,3,4 . Carol Forsblom ${ }^{2,3,4} \cdot$ Ron Liebkind $^{5} \cdot$ Turgut Tatlisumak $^{5,6,7} \cdot$ Lena M. Thorn $^{2,4,8}$. \\ Per-Henrik Groop ${ }^{2,3,4,9}$. Sara Shams ${ }^{10,11,12}$. Jukka Putaala ${ }^{5} \cdot$ Juha Martola ${ }^{1} \cdot$ Daniel Gordin $^{2,3,4,13} \cdot$ FinnDiane Study \\ Group
}

Received: 27 August 2020 / Accepted: 11 January 2021 / Published online: 20 March 2021

(c) The Author(s) 2021

\begin{abstract}
Aims To determine if arterial functional and structural changes are associated with underlying cerebral small vessel disease in neurologically asymptomatic individuals with type 1 diabetes.

Methods We enrolled 186 individuals (47.8\% men; median age 40.0, IQR 33.0 - 45.0 years) with type 1 diabetes (median diabetes duration of 21.6, IQR 18.2-30.3 years), and 30 age- and sex-matched healthy controls, as part of the Finnish Diabetic Nephropathy (FinnDiane) Study. All individuals underwent a biochemical work-up, brain magnetic resonance imaging (MRI), ultrasound of the common carotid arteries and arterial tonometry. Arterial structural and functional parameters were assessed by carotid intima-media thickness (CIMT), pulse wave velocity and augmentation index.

Results Cerebral microbleeds (CMBs) were present in $23.7 \%$ and white matter hyperintensities (WMHs) in $16.7 \%$ of individuals with type 1 diabetes. Those with type 1 diabetes and CMBs had higher median (IQR) CIMT $583(525-663) \mu \mathrm{m}$ than those without $556(502-607) \mu \mathrm{m}, p=0.016)$. Higher CIMT was associated with the presence of CMBs $(p=0.046)$ independent of age, eGFR, ApoB, systolic blood pressure, albuminuria, history of retinal photocoagulation and $\mathrm{HbA}_{1 \mathrm{c}}$. Arterial stiffness and CIMT were increased in individuals with type 1 diabetes and WMHs compared to those without; however, these results were not independent of cardiovascular risk factors.

Conclusions Structural, but not functional, arterial changes are associated with underlying CMBs in asymptomatic individuals with type 1 diabetes.
\end{abstract}

Keywords Carotid intima-media thickness $\cdot$ Arterial tonometry $\cdot$ Cerebral microbleed $\cdot$ Magnetic resonance imaging

\section{Introduction}

Cerebrovascular disease is a common, albeit scarcely studied, vascular complication in individuals with type 1 diabetes (T1D), who have a fourfold risk of stroke compared to non-diabetic individuals [1]. Although cerebrovascular disease in general is considered to mostly affect large arteries supplying the brain, recent data indicate that, in fact, the small cerebral vessels are particularly affected in type 1 diabetes [2]. Cerebral small vessel disease (cSVD) involves

Managed by Massimo Federici .

Per-Henrik Groop

per-henrik.groop@helsinki.fi

Extended author information available on the last page of the article the arterioles, capillaries and venules, with the two most common underlying etiologies being cerebral amyloid angiopathy and hypertensive vasculopathy. Both these etiologies lead to frail microvasculature and an increased risk of intracerebral hemorrhage (ICH). Since the cerebral microvasculature is too small to study per se with neuroimaging, surrogate markers of small vessel disease are employed instead. Magnetic resonance imaging (MRI) findings of cSVD include cerebral microbleeds (CMBs), white matter hyperintensities (WMHs) and lacunar infarcts [3]. We recently showed that cSVD, and especially CMBs, are more common in individuals with type 1 diabetes than in healthy controls [2]. Of note, cSVD has been shown to have a significant impact in type 1 diabetes, as WMHs are associated with cognitive difficulties in these individuals [4], and CMBs are associated with 
increased risk of ischemic and hemorrhagic strokes $[5,6]$ as well as premature mortality in the general population [7].

Structural and functional measures of the cerebrovascular system can give insight into the underlying disease burden and the risk of future events. Measurements such as carotid intima-media thickness (CIMT), pulse wave velocity (PVW) and central augmentation index (AIx) all reflect potential vascular pathology, and their relationship with cSVD in individuals with type 1 diabetes is unknown.

The aim of this study was to determine whether arterial functional and structural changes are associated with cSVD in neurologically asymptomatic individuals with type 1 diabetes.

\section{Methods}

\section{Demographics}

This study was performed as part of the Finnish Diabetic Nephropathy (FinnDiane) Study, a nationwide multicenter study aiming to identify genetic, environmental and clinical risk factors for micro- and macrovascular complications in type 1 diabetes [2]. A total of 191 individuals with type 1 diabetes with an age span ranging from 18 to 50 years and with an onset of diabetes $<40$ years were included. Exclusion criteria were presence of end-stage renal disease, any clinical signs of cerebrovascular disease, as well as contraindications for MRI. Five individuals with type 1 diabetes were excluded due to missing carotid ultrasound data. Thus, a total of 186 individuals with type 1 diabetes were included in the present study. In addition, 30 healthy age- and sexmatched non-diabetic control subjects were recruited. The study was carried out in accordance with the Declaration of Helsinki and approved by the Ethics Committee of the Helsinki and Uusimaa Hospital District. Each participant signed a written informed consent. [2]

All participants were studied at the FinnDiane Research Center (Biomedicum Helsinki) and the Medical Imaging Center at the Helsinki University Hospital. All underwent brain MRI scans, carotid ultrasound, arterial tonometry, blood tests and a thorough clinical examination.

Blood samples were collected to analyze serum creatinine concentrations, serum lipids and lipoproteins (total cholesterol, high-density lipoprotein [HDL], triglycerides and apolipoprotein $\mathrm{B}[\mathrm{ApoB}]$ ), high-sensitivity C-reactive protein (hsCRP) and blood glycated hemoglobin $\left(\mathrm{HbA}_{1 \mathrm{c}}\right)$. The Friedewald equation was used to calculate the low-density lipoprotein (LDL) concentration [8], and the CKD-EPI-formula was used to calculate the estimated glomerular filtration rate (eGFR) [9]. Hypertension was defined as an office measurement of systolic blood pressure $(\mathrm{SBP}) \geq 140$, diastolic blood pressure $(\mathrm{DBP}) \geq 90$ or the use of anti-hypertensive medication. Obesity was defined as body mass index $(\mathrm{BMI}) \geq 30 \mathrm{~kg} / \mathrm{m}^{2}$. Smoking was defined as a history of smoking. Diabetic kidney disease was defined by the urinary albumin excretion rate (UAER) in two out of three timed urine collections as microalbuminuria (UAER $\geq 20<200 \mu \mathrm{g}$ ) or macroalbuminuria $(\mathrm{UAER} \geq 200 \mu \mathrm{g}$ ). The presence of retinopathy was divided into three categories: no retinopathy, presence of any retinopathy and history of retinal photocoagulation. In-depth questionnaires, which have been described previously, were utilized in the collection of clinical data [10]. Of the individuals with type 1 diabetes, two had missing data regarding smoking, five regarding diabetic kidney disease and three regarding retinopathy.

\section{Imaging}

Brain MRI was performed with a 3.0 T scanner (Achieva; Philips, Best, the Netherlands) and included T1, T2, FLAIR, SWI, T2*, DWI, T1 MPRAGE and 3D TOF sequences. Brain MRI images were assessed by an experienced neuroradiologist (JM), who was blinded to all clinical data. Markers of cSVD were rated per the standardized STRIVE criteria, including the assessment of CMBs, WMHs (Fazekas scale used, with category $\geq 1$ considered a significant burden) and lacunar infarcts [11].

\section{Structural and functional arterial measurements}

Carotid ultrasound was performed on the left and right carotid arteries. The distal $1 \mathrm{~cm}$ segment of the common carotid artery segment, immediately before the origin of the bulb was scanned using an ultrasound scanner equipped with a $10 \mathrm{MHz}$ linear probe (MyLab 70, Esaote, Genova, Italy) and implemented with a radiofrequency-based tracking of arterial wall (QIMT®) that allows an automatic and realtime determination of far-wall CIMT $[12,13]$. The mean of two measurements of the left and right CIMT was calculated for the subsequent analyses. Arterial stiffness was estimated by applanation tonometry (SphygmoCor, Atcor Medical, Sydney, NSW, Australia) using a high-fidelity micromanometer (SPC-301; Millar Instruments, Houston, TX) [14]. Pressure waveforms were recorded sequentially at the carotid, femoral and radial artery, with the participant in the supine position and the $\mathrm{R}$ wave of a simultaneous electrocardiography (ECG) recording as reference frame. To calculate central pulse wave velocity (cPWV) and brachial pulse wave velocity (bPWV), the path lengths from the sternal notch to the femoral and radial palpable pulses, respectively, were measured. In addition, three sequential recordings with a minimum of 20 pressure waveforms were recorded from the right radial artery for pulse wave analysis. AIx was calculated from a central pressure waveform, 
generated with a standardized transfer function, as the ratio of the heart rate adjusted augmentation pressure (difference between the second and the first systolic peak) and the central pulse pressure. AIx data were missing from eight individuals, bPWV data from 19 and cPWV data from 30 individuals with type 1 diabetes.

\section{Statistics}

Statistical analysis was done with IBM SPSS Statistics 25.0 (IBM, Armonk, NY). $T$ tests were used for the parametric data presented as means $( \pm \mathrm{SD})$, and Mann-Whitney $\mathrm{U}$ and Kruskal-Wallis tests for the nonparametric data presented as medians (interquartile range). The $X^{2}$ test or Fisher's exact tests were performed for categorical variables. Individuals with type 1 diabetes were subdivided into three groups based on the number of CMBs (zero, one to two, more than two) [15]. Bivariate (Pearson) correlation analysis was used to study correlations between CIMT, arterial stiffness and the number of CMBs and WMHs. Multivariable logistic regression models were built with the arterial parameters (CIMT, bPWV, cPWV and AIx) as independent variables and markers of cSVD as dependent variables and adjusted for clinically relevant risk factors contributing to cerebrovascular disease (age, sex, diabetes duration, BMI, albuminuria, history of retinal photocoagulation, $\mathrm{HbA}_{1 \mathrm{c}}$, eGFR, LDL, ApoB, systolic blood pressure, statin therapy and antihypertensive medication). The threshold for statistical significance was set at $p<0.05$.

\section{Results}

\section{Clinical characteristics}

A total of 186 individuals with type 1 diabetes and 30 healthy age- and sex-matched non-diabetic control subjects were enrolled and met the inclusion criteria for this study, with demographics previously presented [2]. Briefly, the individuals with type 1 diabetes had higher BMI, systolic blood pressure and $\mathrm{HbA}_{1 \mathrm{c}}$, as well as higher hsCRP. The prevalence of CSVD and CMBs was higher in individuals with type 1 diabetes compared to healthy controls. Of the 186 individuals with type 1 diabetes, 64 (34.4\%) had signs of cSVD, 44 (23.7\%) had CMBs, 31 (16.7\%) WMHs and $4(2.2 \%)$ lacunar infarcts (Table 1$)$.

Table 1 The clinical characteristics, prevalence of cSVD and characteristics of arterial structure and function in individuals with type 1 diabetes vs. healthy controls

\begin{tabular}{|c|c|c|c|}
\hline & $\begin{array}{l}\text { Individuals with type } 1 \text { diabe- } \\
\text { tes } N=186\end{array}$ & Controls $N=30$ & $p$ \\
\hline Age, years, median (IQR) & $40.0(33.0-45.0)$ & $38.4(31.4-43.2)$ & 0.475 \\
\hline Male sex, n (\%) & $89(47.8)$ & $13(56.7)$ & 0.646 \\
\hline Diabetes duration, years, median (IQR) & $21.6(18.2-30.3)$ & 0 & - \\
\hline Body mass index, $\mathrm{kg} / \mathrm{m}^{2}$, median (IQR) & $26.2(24.0-28.7)$ & $24.3(22.5-25.5)$ & 0.004 \\
\hline Systolic blood pressure, $\mathrm{mmHg}$, median (IQR) & $129.3(119.0-139.5)$ & $121.0(116.0-128.0)$ & 0.003 \\
\hline $\mathrm{HbA}_{1 \mathrm{c}}, \%$, median $(\mathrm{IQR})$ & $8.1(7.4-8.9)$ & $5.2(4.9-5.4)$ & $<0.001$ \\
\hline Total cholesterol, mmol/L, median (IQR) & $4.4(4.0-4.9)$ & $4.4(4.2-5.5)$ & 0.243 \\
\hline Low-density lipoprotein, mmol/L, median (IQR) & $2.4(2.1-3.0)$ & $2.6(2.1-3.2)$ & 0.156 \\
\hline Triglycerides, mmol/L, median (IQR) & $0.9(0.7-1.4)$ & $0.8(0.7-1.4)$ & 0.640 \\
\hline Apolipoprotein B, g/L, median (IQR) & $67.0(59.0-83.0)$ & $69.0(57.3-94.5)$ & 0.491 \\
\hline High-sensitivity C-reactive protein, mg/L, median (IQR) & $1.2(0.5-2.9)$ & $0.4(0.2-1.5)$ & 0.002 \\
\hline $\mathrm{cSVD}, \mathrm{n}(\%)$ & $64(34.4)$ & $3(10)$ & 0.007 \\
\hline CMBs, n (\%) & $44(23.7)$ & $1(3.3)$ & 0.011 \\
\hline WMHs, n (\%) & $31(16.7)$ & $2(6.7)$ & 0.271 \\
\hline Lacunae, n (\%) & $4(2.2)$ & $0(0)$ & 1.000 \\
\hline CIMT, $\mu \mathrm{m}$, median (IQR) & $566(507-622)$ & $491(458-554)$ & $<0.001$ \\
\hline Central PWV, m/s, median (IQR) & $7.3(6.1-8.8)$ & $6.7(5.3-7.2)$ & 0.003 \\
\hline Brachial PWV, m/s, mean \pm SD & $7.6 \pm 1.3$ & $7.8 \pm 1.1$ & 0.363 \\
\hline AIx, \%, median (IQR) & $14.9(6.6-22.0)$ & $11.5(5.8-19.2)$ & 0.140 \\
\hline
\end{tabular}

$\mathrm{IQR}=$ interquartile range, $\mathrm{CIMT}=$ carotid intima-media thickness, $\mathrm{PWV}=$ pulse wave velocity, $\mathrm{AIx}=$ augmentation index, $\mathrm{cSVD}=\mathrm{cerebral}$ small-vessel disease, $\mathrm{CMBs}=$ cerebral microbleeds, $\mathrm{WMHs}=$ white matter hyperintensities 


\section{CIMT and arterial stiffness in individuals with T1D and healthy control subjects}

CIMT (median [IQR]) (566 [507 - 622] $\mu \mathrm{m}$ vs. 491 [458 $-554] \mu \mathrm{m}, p<0.001)$ and cPWV $(7.3[6.1-8.8] \mathrm{m} / \mathrm{s}$ vs. 6.7 [5.3-7.2] $\mathrm{m} / \mathrm{s}, p=0.003$ ) were higher in individuals with type 1 diabetes compared to healthy controls. No differences in $\operatorname{AIx}(14.9 \%$ [6.6-22.0] vs. $11.5 \%$ [5.8 - 19.2], $p=0.363)$ or bPWV $(7.6 \mathrm{~m} / \mathrm{s} \pm 1.3$ vs. $7.8 \pm 1.1 \mathrm{~m} / \mathrm{s}, p=0.140)$ were observed between the groups. Further, comparisons of cSVD, CIMT and arterial stiffness parameters between the studied groups are presented in Table 1.

\section{CIMT and CSVD}

In individuals with type 1 diabetes, those with cSVD had an increased CIMT compared to those without (582 [537-653] $\mu \mathrm{m}$ vs. 552 [496-601] $\mu \mathrm{m}, p=0.002$ ), as shown in Table 2. Similarly, CIMT was higher in individuals with CMBs (583 $[525-663] \mu \mathrm{m})$ compared to those without (556 [502607] $\mu \mathrm{m}, p=0.016)$ as well as in those with WMHs (580 [549-654] $\mu \mathrm{m}$ ) compared to those with no signs of WMHs (563 [498-613] $\mu \mathrm{m}, p=0.019)$ in brain MRIs. Furthermore, we observed a positive correlation between CIMT and the number of CMBs (Fig. 1).

Table 2 Carotid intima-media thickness and arterial stiffness stratified by small-vessel disease findings in brain MRI in individuals with type 1 diabetes $(n=186)$

\begin{tabular}{|c|c|c|c|c|c|c|c|c|c|}
\hline & \multicolumn{3}{|l|}{ cSVD } & \multicolumn{3}{|l|}{ CMBs } & \multicolumn{3}{|l|}{ WMHs } \\
\hline & $\begin{array}{l}\text { Presence } \\
(n=64)\end{array}$ & $\begin{array}{l}\text { Absence } \\
(n=122)\end{array}$ & $p$ & $\begin{array}{l}\text { Presence } \\
(n=44)\end{array}$ & $\begin{array}{l}\text { Absence } \\
(n=142)\end{array}$ & $p$ & $\begin{array}{l}\text { Presence } \\
(n=31)\end{array}$ & $\begin{array}{l}\text { Absence } \\
(n=155)\end{array}$ & $p$ \\
\hline $\begin{array}{l}\text { CIMT, } \mu \mathrm{m}, \\
\text { median (IQR) }\end{array}$ & $582(537-653)$ & $552(496-601)$ & 0.002 & $583(525-663)$ & $556(502-607)$ & 0.016 & $580(549-654)$ & $563(498-613)$ & 0.019 \\
\hline $\begin{array}{l}\text { Central PWV, } \\
\text { m/s, median } \\
\text { (IQR) }\end{array}$ & $7.9(6.4-9.6)$ & $7.0(6.1-8.1)$ & 0.018 & $7.7(6.2-9.8)$ & $7.3(6.1-8.3)$ & 0.117 & $8.3(7.2-9.6)$ & $7.1(6.1-8.5)$ & 0.013 \\
\hline $\begin{array}{l}\text { Brachial PWV, } \\
\text { m/s, median } \\
\text { (IQR) }\end{array}$ & $7.5(6.8-8.7)$ & $7.5(6.8-8.4)$ & 0.833 & $7.6(6.8-8.8)$ & $7.5(6.7-8.4)$ & 0.518 & $7.7(6.3-8.7)$ & $7.5(6.8-8.4)$ & 0.794 \\
\hline $\begin{array}{l}\text { AIx, \%, median } \\
\text { (IQR) }\end{array}$ & $\begin{array}{l}18.7(11.6- \\
23.4)\end{array}$ & $13.5(5.7-19.3)$ & 0.006 & $\begin{array}{l}19.0(11.3- \\
26.3)\end{array}$ & $14.3(6.4-20.6)$ & 0.015 & $\begin{array}{l}19.6(14.2- \\
23.9)\end{array}$ & $14.3(5.4-21.6)$ & 0.006 \\
\hline
\end{tabular}

$\mathrm{CIMT}=$ carotid intima-media thickness, $\mathrm{PWV}=$ pulse wave velocity, AIx $=$ augmentation index, $\mathrm{cSVD}=$ cerebral small-vessel disease, $\mathrm{CMBs}=$ cerebral microbleeds, $\mathrm{WMHs}=$ white matter hyperintensities

Fig. 1 Carotid intima-media thickness $(\mu \mathrm{m})$ by number of cerebral microbleeds in individuals with type 1 diabetes. Individuals with type 1 diabetes subdivided into three groups based on the number of cerebral microbleeds (zero [ $n=142]$, one to two [ $n=32]$, more than two $[n=12])$ with a CIMT of 556 (502-607) $\mu \mathrm{m}$ vs. 578 (513640) $\mu \mathrm{m}$ vs. 634 (533-737) $\mu \mathrm{m}$, $p=0.028$, respectively

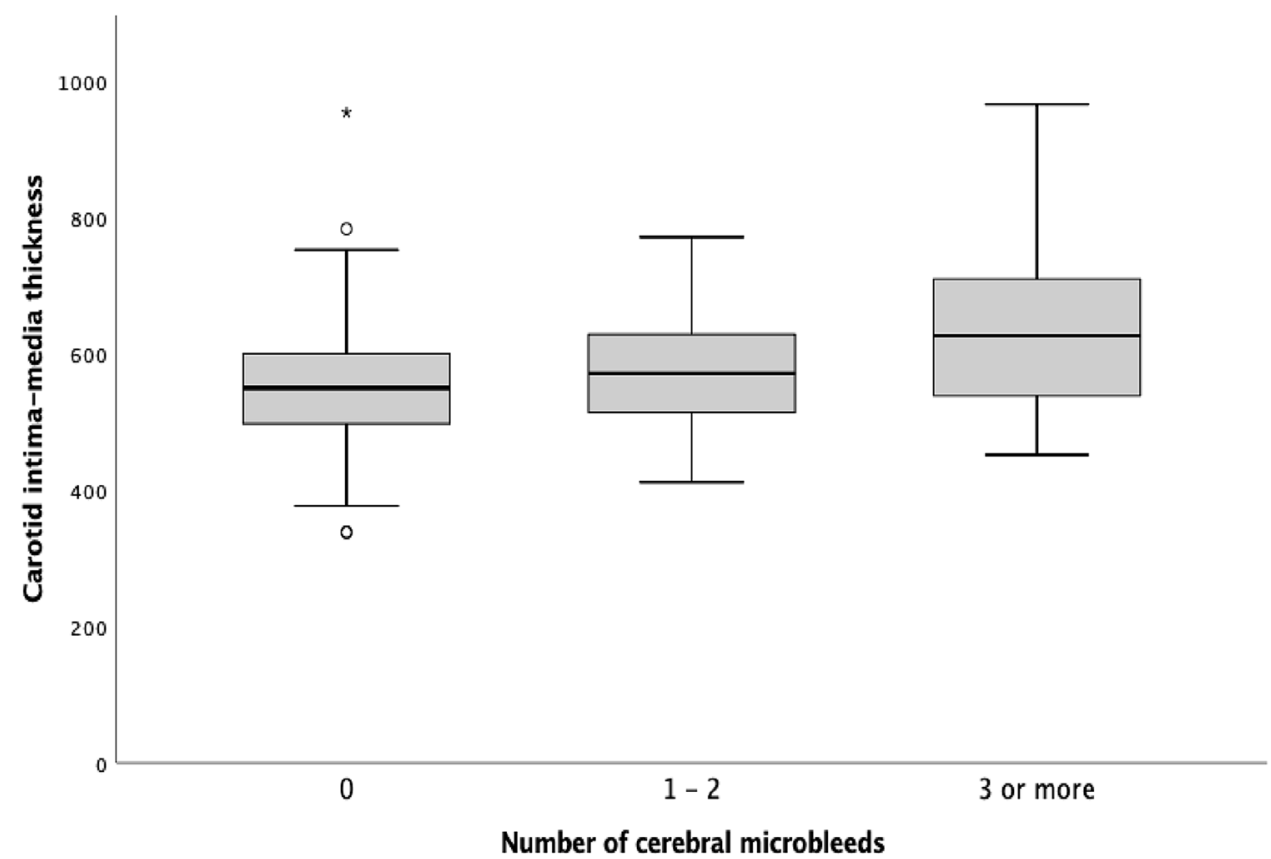


Bivariate correlations between CIMT and the number of CMBs and WMHs in individuals with type 1 diabetes are presented in Supplementary Table 1. Notably, the number of both CMBs $(R=0.157, p=0.032)$ and WMHs $(R=0.203, p=0.005)$ showed significant correlations with CIMT. Lastly, we observed an independent association between CIMT and CMBs in each of the four multivariable models (Model 1: 1.006 [1.001-1.010], $p=0.015$, Model 2: 1.005 [1.000-1.010], $p=0.046$, Model 3: 1.005 [1.001-1.009], $p=0.024$, Model 4: 1.005 [1.001-1.009], $p=0.026$ ) adjusted for clinically relevant risk factors (Table 3).

\section{Arterial stiffness parameters and CSVD}

In individuals with type 1 diabetes, those with cSVD had higher cPWV $(p=0.018)$ and AIx $(p=0.006)$ compared to those without any signs of cSVDs in their brain MRIs. No differences in bPWV were observed between the groups. Specifically, individuals with type 1 diabetes and CMBs had higher AIx $(p=0.015)$ compared to those without CMBs. In contrast, no differences in bPWV or cPWV were observed between these groups. AIx $(p=0.006)$ and cPWV $(p=0.013)$ were elevated in individuals showing signs of WMHs. bPWV did not differ between participants with and without WMHs (Table 2).
Table 3 Multivariable logistic regression analysis of individuals with type 1 diabetes with A) cSVD, B) CMBs and C) WMHs as dependent variables

\begin{tabular}{|c|c|c|c|}
\hline & CIMT & AIx & Central PWV \\
\hline & OR $(95 \% \mathrm{Cl}) ; p$ value & OR $(95 \% \mathrm{Cl}) ; p$ value & OR $(95 \% \mathrm{Cl}) ; p$ value \\
\hline \multicolumn{4}{|l|}{ A) cSVD } \\
\hline Model 1 & $\begin{array}{l}1.004(0.999-1.008) ; \\
p=0.086\end{array}$ & $\begin{array}{l}1.006(0.967-1.046) \\
p=0.778\end{array}$ & $\begin{array}{l}1.075(0.842-1.372) ; \\
p=0.563\end{array}$ \\
\hline Model 2 & $\begin{array}{l}1.003(0.999-1.008) ; \\
p=0.140\end{array}$ & $\begin{array}{l}1.010(0.974-1.048) \\
p=0.579\end{array}$ & $\begin{array}{l}1.029(0.794-1.333) ; \\
p=0.831\end{array}$ \\
\hline Model 3 & $\begin{array}{l}1.004(1.000-1.008) ; \\
p=0.057\end{array}$ & $\begin{array}{l}1.011(0.974-1.049) \\
p=0.577\end{array}$ & $\begin{array}{l}1.085(0.863-1.364) ; \\
p=0.486\end{array}$ \\
\hline Model 4 & $\begin{array}{l}1.005(1.001-1.009) ; \\
p=0.016\end{array}$ & $\begin{array}{l}1.013(0.973-1.054) \\
p=0.538\end{array}$ & $\begin{array}{l}1.113(0.867-1.429) ; \\
p=0.399\end{array}$ \\
\hline \multicolumn{4}{|l|}{ B) $\mathrm{CMBs}$} \\
\hline Model 1 & $\begin{array}{l}1.006(1.001-1.010) \\
p=0.015\end{array}$ & $\begin{array}{l}1.008(0.964-1.054) \\
p=0.718\end{array}$ & $\begin{array}{l}1.105(0.846-1.444) ; \\
p=0.463\end{array}$ \\
\hline Model 2 & $\begin{array}{l}1.005(1.000-1.010) ; \\
p=0.046\end{array}$ & $\begin{array}{l}1.010(0.969-1.053) \\
p=0.637\end{array}$ & $\begin{array}{l}1.102(0.827-1.468) ; \\
p=0.506\end{array}$ \\
\hline Model 3 & $\begin{array}{l}1.005(1.001-1.009) ; \\
p=0.024\end{array}$ & $\begin{array}{l}1.017(0.975-1.061) \\
p=0.433\end{array}$ & $\begin{array}{l}1.077(0.844-1.375) ; \\
p=0.550\end{array}$ \\
\hline Model 4 & $\begin{array}{l}1.005(1.001-1.009) ; \\
p=0.026\end{array}$ & $\begin{array}{l}1.003(0.959-1.049) \\
p=0.893\end{array}$ & $\begin{array}{l}1.117(0.847-1.472) ; \\
p=0.434\end{array}$ \\
\hline \multicolumn{4}{|c|}{ C) WMHs } \\
\hline Model 1 & $\begin{array}{l}1.002(0.997-1.006) ; \\
p=0.496\end{array}$ & $\begin{array}{l}1.032(0.978-1.089) \\
p=0.250\end{array}$ & $\begin{array}{l}1.074(0.804-1.434) ; \\
p=0.631\end{array}$ \\
\hline Model 2 & $\begin{array}{l}1.002(0.997-1.007) ; \\
p=0.451\end{array}$ & $\begin{array}{l}1.049(0.997-1.104) \\
p=0.067\end{array}$ & $\begin{array}{l}1.031(0.749-1.420) ; \\
p=0.851\end{array}$ \\
\hline Model 3 & $\begin{array}{l}1.003(0.998-1.008) ; \\
p=0.213\end{array}$ & $\begin{array}{l}1.038(0.983-1.095) \\
p=0.179\end{array}$ & $\begin{array}{l}1.117(0.836-1.493) ; \\
p=0.454\end{array}$ \\
\hline Model 4 & $\begin{array}{l}1.004(1.000-1.009) ; \\
p=0.065\end{array}$ & $\begin{array}{l}1.052(0.997-1.110) \\
p=0.064\end{array}$ & $\begin{array}{l}1.149(0.854-1.545) ; \\
p=0.360\end{array}$ \\
\hline
\end{tabular}

Model 1: Adjusted for age, sex, eGFR, ApoB and SBP

Model 2: Adjusted for age, eGFR, ApoB, SBP, albuminuria, history of retinal photocoagulation and $\mathrm{HbA}_{1 \mathrm{c}}$ Model 3: Adjusted for age, sex, eGFR, LDL, BMI, $\mathrm{HbA}_{1 \mathrm{c}}$, statin therapy and antihypertensive medication Model 4: Adjusted for sex, eGFR, ApoB, SBP, $\mathrm{HbA}_{1 \mathrm{c}}$ and diabetes duration

$\mathrm{CIMT}=$ carotid intima-media thickness, $\mathrm{PWV}=$ pulse wave velocity, $\mathrm{AIx}=$ augmentation index, $\mathrm{cSVD}=$ cerebral small vessel disease, $\mathrm{CMBs}=$ cerebral microbleeds, $\mathrm{WMHs}=$ white matter hyperintensities, $\mathrm{SBP}=$ systolic blood pressure, eGFR = estimated glomerular filtration rate, $\mathrm{LDL}=$ low-density lipoprotein, $\mathrm{ApoB}=$ apolipoprotein $\mathrm{B}, \mathrm{BMI}=$ body mass index 
Bivariate correlations between arterial stiffness and cSVD changes are presented in Supplementary Table 1. An association was observed between WMHs and cPWV $(p=0.012)$. This correlation was, however, not independent of known cardiovascular risk factors in the multivariable regression analyses (Table 3).

\section{Discussion}

The main finding of this study was the independent association between CIMT and CMBs in young individuals with type 1 diabetes without any clinical signs of neurological disease, indicating a relationship between subclinical systemic atherosclerosis and early-onset microvascular pathology in the brain.

Previous data on the relationship between CIMT and CMBs are conflicting and limited to the general population $[16,17]$. In a community-based study, CIMT was associated with the presence of CMBs in a general population older than our study population [16]. In contrast, another study showed no association between baseline CIMT and CMBs [17].

CIMT is a strong predictor of cardiovascular disease [18]. The observed association between CIMT and CMBs supports the assumption that risk factors for cerebral macrovascular disease are similar to those in preclinical hemorrhageprone cerebral cSVD. CIMT did, however, not correlate independently with WMHs or lacunes in our study. Teasing out the exact risk factors for hemorrhagic and ischemic end events in the brain caused by cSVD is challenging, especially since $\mathrm{CMBs}$ are associated with an increased risk of both intracerebral hemorrhage $(\mathrm{ICH})$ and ischemic stroke, reflecting common underlying mechanisms [7]. Multiple lobar CMBs were seen in the individuals with type 1 diabetes in our study. Lobar CMBs are in turn thought to represent cerebral amyloid angiopathy (CAA), which is one of the most common etiologies causing ICH [5].

Arterial stiffness can be estimated non-invasively using surrogate markers, such as carotid or brachial pulse wave velocity (cPWV and bPWV) and augmentation index (AIx), all available by applanation tonometry. PWV, the gold standard of arterial stiffness, is an established risk factor for cardiovascular disease and mortality in the general population as well as several patient groups [19-23]. In community-based studies, higher PWV has repeatedly been associated with WMHs and brain atrophy, whereas associations with $\mathrm{CMBs}$ and lacunar infarcts are scarce [24-26]. Accelerated arterial stiffening seen in individuals with type 1 diabetes correlates with vascular complications such as diabetic retinopathy, nephropathy and cardiovascular disease [27]. Arterial structure and function have also been found to be associated with a greater risk of cognitive impairment and greater blood pressure pulsatility reflecting a comprehensive association between pathology in the arterial tree and end-organ damage in these patients [28-30].

In our study, arterial stiffness was increased in those with cSVD compared to those without. The finding was, however, not independent of the well-known risk factors for arterial disease in type 1 diabetes. This observation differs from that in a previous study showing aortic stiffness to be independently associated with WMHs [31]. The contradiction between these results is not fully clear but might be due to differences in age, diabetes duration and the prevalence of WMHs. Mechanisms other than hemodynamic status such as low-grade inflammation and reactive oxygen species known to be related to vascular disease in type 1 diabetes may explain the lack of association [32]. The complexity of the cross-talk between diabetes and arterial function and structure may also involve endothelial dysfunction, this effect being possibly mediated via kidney damage [33, 34]. Diabetes mellitus has been suggested to associate with dysfunction of the blood-brain barrier [35]. Whether or not blood-brain barrier dysfunction relates to cSVD, and especially to CMBs, is an interesting topic and deserves more research.

Our study findings raise intriguing future research topics relating systemic arterial functional and structural changes to the cerebrovasculature and the relation of these finding into a broader perspective of early arterial aging and accelerated by diabetes [36-38].

This study does not go without limitations. Although our study is, to the best of our knowledge, the largest to assess the relationship between vascular structural and functional parameters and cSVD in individuals with type 1 diabetes to date, an even larger study would enable greater statistical power. We observed an association between CIMT, an acknowledged marker of atherosclerosis and strong predictor of CVD, and $\mathrm{CMBs}$ that was independent of a number of risk factors for these entities. By studying an even larger cohort, we may have been able to detect associations between arterial functional (arterial stiffness) variables and other cerebrovascular pathology observed in the individuals with type 1 diabetes. The limited number of control subjects in our study can cause a potential type 2 error in statistical analysis. Further, acknowledging the cross-sectional study design, we can only speculate about causal relationships. Follow-up studies are needed to gain insight into the causality of risk factors. The strengths of this study are the standardized imaging and clinical assessment, as well as the strong phenotypic data.

\section{Conclusion}

Our study shows that vascular structural changes, assessed by CIMT, are associated with the presence of CMBs in individuals with type 1 diabetes, independently of relevant 
clinical covariates. We did not observe an independent association between functional and structural vascular changes and the overall presence of cSVD. The main finding of this study suggests that CIMT, which is readily available in a clinical setting, adds to risk prediction of early preclinical cerebrovascular disease in individuals with type 1 diabetes. This approach, part of a detailed work-up aiming to individualize treatment in individuals with type 1 diabetes, is feasible in various settings. This may be important considering that these patients are frequently managed by different health professionals possibly altering the quality of care. This may be of special interest for the care of individuals in need of antithrombotic medication, another risk factor for hemorrhage in the brain, as well as for offering more aggressive non-medical prophylactic approaches for individuals with subclinical increased risk for vascular disease.

Supplementary Information The online version contains supplementary material available at (https://doi.org/10.1007/ s00592-021-01678-x).

Acknowledgements The authors deeply acknowledge the technical assistance of Anna Sandelin, Jaana Tuomikangas and Mira Korolainen. They also thank Pentti Pölönen, HUS Medical Imaging Center, Helsinki University Hospital, for performing the MRI scans.

Author contributions J.I., A.T., C.F., R.L., T.T., L.M.T., P-H.G., S.S., J.P., J.M. and D.G. contributed to the study design and acquisition of data, as well as the interpretation of data. J.I., A.T., J.M., J.P. and D.G. had the main responsibility for analyzing data and writing the first draft of the paper. J.I., A.T., C.F., R.L., T.T., L.M.T., P-H.G., S.S., J.P., J.M. and D.G. critically revised the manuscript. P-H.G is the guarantor of this work and, as such, had full access to all the data in the study and takes responsibility for the integrity of the data and the accuracy of the data analysis.

Funding Open Access funding provided by University of Helsinki including Helsinki University Central Hospital. The FinnDiane study was supported by grants from Folkhälsan Research Foundation, Academy of Finland (316664), Wilhelm and Else Stockmann Foundation, "Liv och Hälsa" Society, Novo Nordisk Foundation (NNF OC0013657), Sigrid Juselius Foundation, Päivikki and Sakari Sohlberg Foundation, Finnish Foundation for Cardiovascular Research and by governmental research funding. A.T. was supported by the Biomedicum Helsinki Foundation and the Medical Society of Finland (Finska Läkaresällskapet). D.G. was supported by Wilhelm and Else Stockmann Foundation, "Liv och Hälsa" Society, Medical Society of Finland (Finska Läkaresällskapet), Dorothea Olivia, Karl Walter and Jarl Walter Perklén's Foundation, Päivikki and Sakari Sohlberg Foundation, Sigrid Juselius Foundation, the University of Helsinki (Clinical Researcher stint) and the Academy of Finland (UAK10121MRI). None of the funding bodies had any role in the study design; collection, analysis or interpretation of data; writing of the manuscript; or the decision to submit the manuscript for publication.

Data Availability The database is available for all FinnDiane researchers.

Code availability Not applicable.

\section{Compliance with ethical standards}

Conflicts of interest D.G. Lecture or advisory honoraria: AstraZeneca, Boehringer Ingelheim, Delta Medical Communications, Fresenius, GE Healthcare, Novo Nordisk. Support to attend medical meetings: CVRx., Sanofi Aventis. J.M. Lecture Honoria Santen. P.-H.G. has received lecture honoraria from AstraZeneca, Boehringer Ingelheim, Eli Lilly, Elo Water, Genzyme, Medscape, Merck Sharp \& Dohme (MSD), Mundipharma, Novartis, Novo Nordisk, PeerVoice, Sanofi, SCIARC and is an advisory board member of AbbVie, Bayer, Boehringer Ingelheim, Eli Lilly, Janssen, Medscape, MSD, Novartis, Novo Nordisk and Sanofi. No other potential conflicts of interest relevant to this article were reported.

Ethics approval The study was carried out in accordance with the Declaration of Helsinki and approved by the Ethics Committee of the Helsinki and Uusimaa Hospital District.

Consent to participate Each participant signed a written informed consent before participation.

Consent for publication Not applicable.

Open Access This article is licensed under a Creative Commons Attribution 4.0 International License, which permits use, sharing, adaptation, distribution and reproduction in any medium or format, as long as you give appropriate credit to the original author(s) and the source, provide a link to the Creative Commons licence, and indicate if changes were made. The images or other third party material in this article are included in the article's Creative Commons licence, unless indicated otherwise in a credit line to the material. If material is not included in the article's Creative Commons licence and your intended use is not permitted by statutory regulation or exceeds the permitted use, you will need to obtain permission directly from the copyright holder. To view a copy of this licence, visit http://creativecommons.org/licenses/by/4.0/.

\section{References}

1. Janghorbani M, Hu FB, Willett WC et al. (2007) Prospective study of type 1 and type 2 diabetes and risk of stroke subtypes: the Nurses' Health Study. Diabetes Care 30(7):1730-1735. https:// doi.org/10.2337/dc06-2363

2. Thorn LM, Shams S, Gordin D et al. (2019) Clinical and MRI Features of Cerebral Small-Vessel Disease in Type 1 Diabetes. Diabetes Care 42(2):327-330. https://doi.org/10.2337/dc18-1302

3. Cuadrado-Godia E, Dwivedi P, Sharma S et al. (2018) Cerebral Small Vessel Disease: A Review Focusing on Pathophysiology, Biomarkers, and Machine Learning Strategies. J Stroke 20(3):302-320. https://doi.org/10.5853/jos.2017.02922

4. Nunley KA, Ryan CM, Orchard TJ et al. (2015) White matter hyperintensities in middle-aged adults with childhood-onset type 1 diabetes. Neurology 84(20):2062-2069

5. Akoudad S, Portegies ML, Koudstaal PJ et al. (2015) Cerebral microbleeds are associated with an increased risk of stroke: the rotterdam study. Circulation 132(6):509-516. https://doi.org/10. 1161/CIRCULATIONAHA.115.016261

6. Lee J, Sohn EH, Oh E, Lee AY (2018) Characteristics of Cerebral Microbleeds. Dement Neurocogn Disord 17(3):73-82. https://doi. org/10.12779/dnd.2018.17.3.73

7. Charidimou A, Shams S, Romero JR et al. (2018) Clinical significance of cerebral microbleeds on MRI: A comprehensive 
meta-analysis of risk of intracerebral hemorrhage, ischemic stroke, mortality, and dementia in cohort studies (v1). Int J Stroke 13(5):454-468. https://doi.org/10.1177/1747493017751931

8. Warnick GR, Knopp RH, Fitzpatrick V, Branson L (1990) Estimating low-density lipoprotein cholesterol by the Friedewald equation is adequate for classifying patients on the basis of nationally recommended cutpoints. Clin Chem 36(1):15-19

9. Levey AS, Inker LA, Coresh J (2014) GFR estimation: from physiology to public health. Am J Kidney Dis 63(5):820-834. https:// doi.org/10.1053/j.ajkd.2013.12.006

10. Groop PH, Thomas MC, Moran JL et al. (2009) The presence and severity of chronic kidney disease predicts all-cause mortality in type 1 diabetes. Diabetes 58(7):1651-1658. https://doi.org/10. 2337/db08-1543

11. Wardlaw JM, Smith EE, Biessels GJ et al. (2013) Neuroimaging standards for research into small vessel disease and its contribution to ageing and neurodegeneration. The Lancet Neurology 12(8):822-838. https://doi.org/10.1016/s1474-4422(13)70124-8

12. Kozakova M, Morizzo C, Goncalves I, Natali A, Nilsson J, Palombo C (2019) Cardiovascular organ damage in type 2 diabetes mellitus: the role of lipids and inflammation. Cardiovasc Diabetol 18(1):61. https://doi.org/10.1186/s12933-019-0865-6

13. Wyman RA, Fraizer MC, Keevil JG et al. (2005) Ultrasounddetected carotid plaque as a screening tool for advanced subclinical atherosclerosis. Am Heart J 150(5):1081-1085. https://doi.org/ 10.1016/j.ahj.2005.01.010

14. Wilkinson IB, Fuchs SA, Jansen IM et al. (1998) Reproducibility of pulse wave velocity and augmentation index measured by pulse wave analysis. J Hypertens 16(12 Pt 2):2079-2084. https://doi.org/ 10.1097/00004872-199816121-00033

15. Ding J, Sigurðsson S, Jónsson PV et al. (2017) Space and location of cerebral microbleeds, cognitive decline, and dementia in the community. Neurology 88(22):2089-2097

16. Chung CP, Chou KH, Chen WT et al. (2017) Location of Cerebral Microbleeds And Their Association with Carotid Intimamedia Thickness: A Community-based Study. Sci Rep 7(1):12058. https://doi.org/10.1038/s41598-017-12176-y

17. Romero JR, Preis SR, Beiser A et al. (2016) Carotid Atherosclerosis and Cerebral Microbleeds: The Framingham Heart Study. J Am Heart Assoc 5(3):e002377. https://doi.org/10.1161/JAHA. 115.002377

18. Naqvi TZ, Lee MS (2014) Carotid intima-media thickness and plaque in cardiovascular risk assessment. JACC Cardiovasc Imaging 7(10):1025-1038. https://doi.org/10.1016/j.jcmg.2013.11.014

19. Willum-Hansen T, Staessen JA, Torp-Pedersen C et al. (2006) Prognostic value of aortic pulse wave velocity as index of arterial stiffness in the general population. Circulation 113(5):664-670. https://doi.org/10.1161/CIRCULATIONAHA.105.579342

20. van Sloten TT, Schram MT, van den Hurk K et al. (2014) Local stiffness of the carotid and femoral artery is associated with incident cardiovascular events and all-cause mortality: the Hoorn study. J Am Coll Cardiol 63(17):1739-1747. https://doi.org/10. 1016/j.jacc.2013.12.041

21. Laurent S, Boutouyrie P, Asmar R et al. (2001) Aortic stiffness is an independent predictor of all-cause and cardiovascular mortality in hypertensive patients. Hypertension 37(5):1236-1241

22. Cruickshank K, Riste L, Anderson SG, Wright JS, Dunn G, Gosling RG (2002) Aortic pulse-wave velocity and its relationship to mortality in diabetes and glucose intolerance: an integrated index of vascular function? Circulation 106(16):2085-2090. https://doi. org/10.1161/01.cir.0000033824.02722.f7

23. Vlachopoulos C, Aznaouridis K, Stefanadis C (2010) Prediction of cardiovascular events and all-cause mortality with arterial stiffness: a systematic review and meta-analysis. J Am Coll Cardiol 55(13):1318-1327. https://doi.org/10.1016/j.jacc.2009.10.061

24. Palta P, Sharrett AR, Wei J et al. (2019) Central Arterial Stiffness Is Associated With Structural Brain Damage and Poorer Cognitive
Performance: The ARIC Study. J Am Heart Assoc 8(2):e011045. https://doi.org/10.1161/JAHA.118.011045

25. Zhai FF, Ye YC, Chen SY et al. (2018) Arterial stiffness and cerebral small vessel disease. Front Neurol 9:723. https://doi.org/10. 3389/fneur.2018.00723

26. Poels MM, Zaccai K, Verwoert GC et al. (2012) Arterial stiffness and cerebral small vessel disease: the rotterdam scan study. Stroke 43(10):2637-2642. https://doi.org/10.1161/STROKEAHA.111. 642264

27. Gordin D, Waden J, Forsblom C et al. (2012) Arterial stiffness and vascular complications in patients with type 1 diabetes: the Finnish Diabetic Nephropathy (FinnDiane) Study. Ann Med 44(2):196-204. https://doi.org/10.3109/07853890.2010.530681

28. Scuteri A, Wang H (2014) Pulse wave velocity as a marker of cognitive impairment in the elderly. J Alzheimers Dis 42(Suppl 4):S401-410. https://doi.org/10.3233/jad-141416

29. Scuteri A, Morrell CH, Orru M et al. (2016) Gender specific profiles of white coat and masked hypertension impacts on arterial structure and function in the SardiNIA study. Int J Cardiol 217:92-98. https://doi.org/10.1016/j.ijcard.2016.04.172

30. Scuteri A, Rovella V, Alunni Fegatelli D, Tesauro M, Gabriele M, Di Daniele N (2018) An operational definition of SHATS (Systemic Hemodynamic Atherosclerotic Syndrome): Role of arterial stiffness and blood pressure variability in elderly hypertensive subjects. Int J Cardiol 263:132-137. https://doi.org/10.1016/j. ijcard.2018.03.117

31. van Elderen SG, Brandts A, Westenberg JJ et al. (2010) Aortic stiffness is associated with cardiac function and cerebral small vessel disease in patients with type 1 diabetes mellitus: assessment by magnetic resonance imaging. Eur Radiol 20(5):1132-1138. https://doi.org/10.1007/s00330-009-1655-4

32. Pantoni L, Garcia JH (1997) Pathogenesis of Leukoaraiosis: a review. Stroke 28(3):652-659

33. Scuteri A, Stuehlinger MC, Cooke JP, Wright JG, Lakatta EG, Anderson DE, Fleg JL (2003) Nitric oxide inhibition as a mechanism for blood pressure increase during salt loading in normotensive postmenopausal women. J Hypertens 21(7):1339-1346. https://doi.org/10.1097/00004872-200307000-00023

34. Marfella R, Sasso FC, Siniscalchi M et al. (2012) Peri-procedural tight glycemic control during early percutaneous coronary intervention is associated with a lower rate of in-stent restenosis in patients with acute ST-elevation myocardial infarction. J Clin Endocrinol Metab 97(8):2862-2871. https://doi.org/10.1210/jc. 2012-1364

35. Prasad S, Sajja RK, Naik P, Cucullo L (2014) Diabetes Mellitus and Blood-Brain Barrier Dysfunction: An Overview. J Pharmacovigil 2(2):125. https://doi.org/10.4172/2329-6887.1000125

36. Calimport SRG, Bentley BL, Stewart CE et al. (2019) To help aging populations, classify organismal senescence. Science 366(6465):576-578. https://doi.org/10.1126/science.aay7319

37. Nilsson PM, Laurent S, Cunha PG et al. (2018) Characteristics of healthy vascular ageing in pooled population-based cohort studies: the global Metabolic syndrome and Artery REsearch Consortium. J Hypertens 36(12):2340-2349. https://doi.org/10.1097/ HJH.0000000000001824

38. Ronnback M, Fagerudd J, Forsblom C, Pettersson-Fernholm K, Reunanen A, Groop PH, Finnish Diabetic Nephropathy Study G (2004) Altered age-related blood pressure pattern in type 1 diabetes. Circulation 110(9):1076-1082. https://doi.org/10.1161/01. CIR.0000139903.29522.8D

Publisher's Note Springer Nature remains neutral with regard to jurisdictional claims in published maps and institutional affiliations. 


\section{Authors and Affiliations}

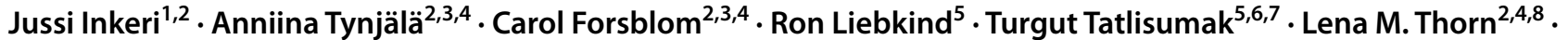 Per-Henrik Groop ${ }^{2,3,4,9}$. Sara Shams ${ }^{10,11,12}$. Jukka Putaala ${ }^{5} \cdot$ Juha Martola ${ }^{1} \cdot$ Daniel Gordin ${ }^{2,3,4,13} \cdot$ FinnDiane Study Group}

$1 \quad$ HUS Medical Imaging Center, Radiology, University of Helsinki and Helsinki University Hospital, Helsinki, Finland

2 Folkhälsan Institute of Genetics, Folkhälsan Research Center, Helsinki, Finland

3 Abdominal Center, Nephrology, University of Helsinki and Helsinki University Hospital, Helsinki, Finland

4 Research Program for Clinical and Molecular Metabolism, University of Helsinki, Helsinki, Finland

5 Neurology, University of Helsinki and Helsinki University Hospital, Helsinki, Finland

6 Department of Clinical Neuroscience/Neurology, Institute of Neuroscience and Physiology, Sahlgrenska Academy, University of Gothenburg, Gothenburg, Sweden

7 Department of Neurology, Sahlgrenska University Hospital, Gothenburg, Sweden
8 Department of General Practice and Primary Health Care, University of Helsinki and Helsinki University Hospital, Helsinki, Finland

9 Department of Diabetes, Central Clinical School, Monash University, Melbourne, Australia

10 Department of Radiology, Karolinska University Hospital, Stockholm, Sweden

11 Department of Clinical Neuroscience, Karolinska Institute, Stockholm, Sweden

12 Department of Radiology, Stanford University, Stanford, CA, USA

13 Joslin Diabetes Center, Harvard Medical School, Boston, MA, USA 